\title{
DESARRAIGO Y EXPERIENCIA: LECTURAS SOBRE PAUL RICOEUR Y PHILIPE CLAUDEL
}

\author{
M Cristina Sánchez León \\ EMUI_EuroMedUniversity ${ }^{1}$
}

http://dx.doi.org/10.5209/rev NOMA.2016.v47.n1.52400

Resumen.- Muchas veces nos preguntamos cuál es el papel o el rol que los intelectuales, académicos o artistas pueden cumplir en países y entornos de conflicto, para este caso específico, países y entornos que no cuentan con una protección real tanto de su integridad como de la satisfacción de sus necesidades básicas y especiales. Más allá de establecer cuál sea el modo como los artistas, intelectuales o académicos pueden contribuir a la satisfacción de dichos requerimientos, en este artículo se pretende sentar una posición sobre la importancia que adquieren las formas simbólicas y reflexionadas en las que los escritores sin importar que sean filósofos o literatos, dejan puesta la crudeza de lo que pasa y adviene a los espíritus solitarios cuya soledad impuesta y causada, nunca elegida, se les aparece como forma de vida. El caso de PhilippeClaudel y el caso de Paul Ricoeur, son escogidos así para el presente artículo como diálogos incesantes de las maneras en las que el desarraigo da qué pensar sobre todo para los que vemos como los diferentes títulos le son asignados a experiencias de violencia.

Palabras clave: Desarraigo, narración, narrativa, narrador, silencio, Pihilippe Claudel, Paul Ricoeur

\begin{abstract}
We often wonder what is the role or the role that intellectuals, academics and artists can play in countries and conflict environments, for this specific case, countries and environments that do not have real protection both its integrity and satisfaction their basic and special needs. Beyond establishing what mode as artists, intellectuals and academics can contribute to meeting these requirements, this article is intended to establish a position on the importance acquired symbolic forms and reflected in the writers regardless whether philosophers or writers, let put the rawness of what happens and there comes the lonely spirits whose loneliness imposed and caused never chosen, appears to them as a lifestyle. For Philippe Claudel and the case of Paul Ricoeur, they are thus chosen for this article as incessant dialogues of the ways in which the rootlessness provides food for thought especially for those we see as different titles you are assigned to experiences of violence.
\end{abstract}

Keywords: Rootlessness, narration, narrative, narrator, silence, Philippe Claudel, Paul Ricoeur

Pensar en la aldea, aunque sea en pasado, es un poco como estar en ella, pese a saber que ya no existe, que todas las casas, que todas las casas fueron quemadas y destruidas, que todos los animales, perros, cerdos, patos $y$ gallinas, han muerto como la mayoría de sus habitantes, y que los supervivientes se han dispersado por los cuatro rincones del mundo. [PhilippeClaudel, La Nieta del señor Lihn]

\footnotetext{
${ }^{1}$ http://www.ucm.es/emui/m-cristina-sanchez-leon
} 
La obra de la artista colombiana Erika Diettes se ha caracterizado por integrar a su forma e interés, la problemática de la relación entre memoria y violencia. Obras como "Río Abajo", "Agua a punto de sangre" y "Sudarios", condensan la experiencia del vínculo entre el dolor y la ausencia, como esas experiencias que sólo parecen leerse a través de una muerte violenta, y aquello que puede parecer peor, un fenómeno de desaparición. Potencia simbólica y fuerza narrativa se constituyen así en el tránsito que existe entre materialidad y poética. Materialidad inevitable de esa reminiscencia,cuyos testigos son los familiares que han prestado la ropa de sus desaparecidos.

La artista señala que para la realización de su obra Río abajo, los familiares le hicieron entrega de la ropa limpia, impecable, "como si esa ropa requiriera ser vestida", señala. Hay entonces en esta escena una poética del olvido, si nos detenemos a revisar la fugacidad de cada una de las piezas de ropa fotografiadas en el agua, su itinerario y lo que no tiene marcha atrás.

Comienzo la lectura de este trabajo haciendo mención de la obra de esta artista rescatando precisamente la plasticidad que el lenguaje aporta desde la fotografía como forma narrativa del espectro, figura en exceso conocida por filósofos y escritores, y figura, en este caso, recuperada con la presencia de mujeres que fueron testigos de las torturas de sus cercanos. Bajo la forma del espectro aparecemos en algunas ocasiones cuando vivimos el destierro, el exilio y la segregación como el despotismo más directo en el despojo de lo que somos.

Recurro a Erika Diettes con el fin de ubicar la discusión que me interesa dar en esta mañana, aquella en donde propongo leer la figura del desarraigo como la aniquilación de la costumbre y por ello, la aniquilación de la experiencia, cuestión que encuentro de forma evidentísima en la obra La nieta del señor Lihndel francés Philippe Claudel. Por otro lado, pero en la misma dirección, llama mi atención que en repetidas ocasiones y en consonancia con los abordajes sobre la memoria como un problema filosófico, se recurre a Paul Ricoeur, con el fin de soportar discusiones sobre la identidad narrativa como una categoría que permite el encuentro del sujeto hablante como sujeto narrador y como sujeto de experiencia. De allí que Ricoeur se haya convertido en uno de los filósofos más importantes para volver sobre el problema del testigo, del testimonio y, por su puesto de las potencias y vicios de lo que suele entenderse por memoria.

Estos abordajes no dejan de ser interesantes e inevitables. Sin embargo, quisiera proponer el modelo fracturado, si se quiere denominar así, que en Ricoeur está presente en sus fragmentos "Vivo hasta la muerte" obra editada a partir de borradores, intuiciones e ideas propias de los pensamientos próximas a su muerte, y a su conferencia La vida: un relato en búsqueda de narrador; ello, con el fin de enfatizar algo distinto aunque no lejano, a la identidad narrativa.

Me refiero a la noción de trama que Ricoeurfundamenta en Aristóteles, y que sirve para revisar la figura del desarraigo como la escena en la que se extingue 
la raíz o el origen, es decir, la costumbre, aquí quiero referirme a esta instancia de forma primordial. De forma curiosa nos enfrentamos a una paradójica dimensión del mundo narrativo: por un lado el desarraigo como separación y expulsión de lo propio, es decir, de lo que aquí llamaremos la costumbre o lo acostumbrado y que, por la fractura afectiva o emocional que sobreviene con la narración hace emerger la imposibilidad de narrar, y, por otro lado el desarraigo como lugar en donde toda potencia simbólica se ve restituida.

Mientras que para Ricoeur la trama constituye un proceso integrador en donde el lector de una obra deviene espectador de la vida; en Claudel la travesía del caminante refugiado, el Señor Lihn configura la escena de la incertidumbre que en definitiva acentúa la esencia de quien se mantiene a la espera y a la expectativa, claro está no como forma de curiosidad, sino como profundo temor hacia lo nuevo. Sin embargo no podríamos olvidar que el itinerario del Señor Lihnes lo que permite una nueva forma de arraigo y quizá sea esta instancia la que nos parezca fundamental para representarnos la restitución de la potencia simbólica: el refugiado avanza en su camino, pero de forma constante se aferra a lo que queda de su familia, una niñita de brazos cuyo rostro solo se revela al final de la obra: "Ahora el señor Lihn es viejo, y está cansado. Aquel país desconocido lo agota. la muerte lo agota. Lo ha chupado como los ávidos cabritillos a su madre, que se tumba sobre un costado porque no puede más. La muerte se lo ha quitado todo. No le queda nada. Está amiles de kilómetros de una aldea que ya no existe, a miles de kilómetros de unas tumbas huérfanas de sus cuerpos, muertos a unos pasos de ellas. Está a miles de días de una vida que antaño fue hermosa y feliz" P. 33

En este sentido el desarraigo, figura eminentemente demoledora de la certeza, genera unos vínculos narrativos que se mueven y se agencian en otra escala. Así como Claudel muestra esa amistad nacida entre Tao LaiLhin y Bark, sólo a partir de una conversación monosílaba que tiene lugar en un banco de "cualquier" parque; así mismo aparecen otras escenas de fractura de las nuevas relaciones desarraigadas que crean un tipo especial de filiación: somos lo mismo, porque venimos de lo mismo, es decir, de la guerra. La guerra nos hace iguales, nuestra forma de habitar es la guerra, y desde ahí nuestra potencia narrativa es homogénea, quizá homogeneizante.

Pareciera que el desarraigo permite o encausa una especie de muerte, incluso, una muerte de lo que somos. Quizá la experiencia límite es que aún cuando morimos al nicho de la costumbre nos preparamos para hacer parte del tránsito de lo nuevo. Creo en las muchas muertes y por ello sostengo que Ricoeur, justo al final nos instala en esta polifonía: "¿Qué es morir para el existente? Es disociar en el nombre propio lo inmortal, retirándose de la obra para él terminada. Los dos tiempos, el de la obra y el de la vida, que hasta aquí se habían superpuesto, se desunen: el existente que pinta abandona el tiempo inmortal de la obra y se repliega en el tiempo inmortal de la vida (inmortal no quiere decir eterno, sino no marcado por la mortalidad del ser viviente)".

El desarraigo, ya lo hemos dicho, encarna la desaparición de la confianza, la perdida de lo acostumbrado entendido como la corroboración imperativa de una inclinación y ello, no puede definirse sino como lo afirma Claudel: venir al mundo por segunda vez. 
La formación de espectros y las figuras de lo siniestro no escapan a la trayectoria del desarraigo, y más si pensamos en la forma como la trama del desarraigo se configura: síntesis de lo heterogéneo que imprime un nuevo tiempo, aparición de un tiempo plural. En Ricoeur lo podemos entender así: "Aristóteles no dudaba en decir que toda historia bien narrada enseña algo; más bien, decía que la historia revela aspectos universales de la condición humana y que, a este respecto, la poesía era más filosófica que la Historia de los historiadores, mucho más dependiente de los aspectos anecdóticos de la vida. Sea cual sea esta relación entre la poesía y la historiografía, es cierto que la tragedia, la epopeya, la comedia —por no citar más que los géneros conocidos por Aristóteles- desarrollan una clase de inteligencia que podemos denominar inteligencia narrativa, que se encuentra más cerca de la sabiduría práctica y del juicio moral que de la ciencia y, en un sentido más general, del uso teórico de la razón". (conferencia)

En razón de esta afirmación quiero referir el valor que tiene la culminación de la novela de Claudel: Sang Diu, mañana dulce traducción del nombre, nieta del señor Lihn, es la manifestación del arraigo ficcional. La cara dulce y el vestido impecable después de un largo sufrimiento y padecer, no es más que la esperanza del lector que quiere y espera un rostro limpio en toda la historia. Sang Diu es el espectro hecho esperanza, SangDiú, deviene arraigo porque no es real, la nieta del señor Lihn es una muñeca salvada de la guerra.

Todo acontece en la novela en los lugares de la movilidad como si la experiencia de lo mutable que se diera en un espacio fuera la manifestación de las almas humanas. La figura del desarraigo que quizá para muchos creadores en la literatura ha sido tan abordada, sentida y trabajada, se vuelve así el modo de pensar en una narrativa del "me quedé sin mí" y del "me quedé sin alma, sin lugar, sin abrigo". A quien sobreviene la muerte injusta, malograda y absurda se le vuelve una señal del desarraigo una huella del "me quedé sin ti, porque me quedé sin mi".

A menudo nos preguntamos cuál es la pretensión narrativa, si cabe denominarlo así, de quienes escriben o narran. La idea se nos aparece en un escenario donde la consideración y la reflexión que exige la escritura, no se parece en nada a la versatilidad y exigencia que plantea el mundo oral. Hago esta afirmación en virtud de que vale la pena preguntar qué narra quien narra, o que es lo que acontece en el umbral del mundo narrativo y del mundo experiencial.

Ahora dos cuestiones que servirán sin duda para trabajos de posterior reflexión, quizá aquella reflexión sobre una especie de vivencia del desarraigo como una suerte de expectativa documental como expectativa narrativa.

\section{Apuntes sobre la visión del silencio}

En varias ocasiones suele pensarse que independientemente de los factores asociados a la imaginación, a la reproducción y a la representación de la vida humana, la literatura no ofrece una utilidad radical frente a otras áreas del conocimiento o de la reflexión estética. Sin embargo años de profunda indagación por parte de destacados filósofos y escritores han demostrado que 
hay diversos modos o lentes desde los cuáles la sabiduría narrativa, como quiero denominarla aquí, representa un motor de sentido en la comprensión de la vida como acontecimiento, de la vida de los pueblos como formas simbólicas, de la historia como historia particular, etc. El hecho de evidenciar el tránsito o la trayectoria que hay entre palabra dicha y texto escrito es lo que a Ricoeursiguiendo a Benjamin, le representa la piedra angular de una reflexión sobre las formas de la temporalidad o más bien, sobre las formas desde las cuales el tiempo puede ser asumido, por qué no, escuchado.

La vida del narrador puede explicarse desde la distancia que lo constituye, distancia que se vuelve exigencia y necesariedad, pues curiosamente es la distancia con las cosas del tiempo lo que permite articular la narración: cuento aquello que me representa distancia, quizá lejanía, cuento o narro cuando se desplaza la importancia de la verificabilidad por la importancia de la experiencia. Quizá sea ese el temor del crítico alemán, pues es la experiencia lo que tiende a desaparecer cuando tras la guerra o circunstancias violentas y deplorables, no queda sino el silencio como alternativa. Claro está, para nosotros es una tarea, no solamente pensar en el drama de los silenciamientos políticos o sociales.

La expresión que utiliza Benjamin bien nos podría servir para imaginar cuál es el modo de entender la narración: llevar de boca en boca no es sólo trasladar la versión sino mantener y continuar el acontecimiento con oídos distintos, casi que podríamos discutir sobre la figura de quien aporta novedad:¿son las palabras, son los oídos, o son los diálogos que surgen incluso cuando traslado la experiencia del narrador a la del oyente?

Dos figuras son así las que a nuestros ojos parecen fundamentales: por un lado la figura del narrador contempla ese viajero, ese personaje que viene de lejos, al que el viaje le sucede; por otro lado está el narrador que se queda en su país, en su casa como el conocedor virtuoso que adquiere la imagen de testigo. Las dos figuras se truecan en dos cuestiones que para una reflexión posterior, puede ser básica: el conocimiento de la cultura, puede aparecer por las dos vías y la dimensión histórica sólo se alcanza en la fusión de estas dos figuras "curiosamente" temporales. Aldeanos y marinos, para nuestro caso, el vínculo entre nómadas y sedentarios que cultivan y cuyo arrojo está evidenciado en el comportamiento diario que trae incluso el azar, son personajes que constituyen esa historia de enseñanza de la noticia lejana.

Peregrinos, viajeros, nómadas, aventureros y habitantes, son denominaciones que no sólo hacen parte del trabajo literario si por ello concebimos el que cuenta simplemente como le fue en su viaje, más que esto, son "personalidades" o "figuraciones" de la historia particular que como Benjamin dice, adquiere suprema utilidad moral. ¿Cuál sea la manera como debamos vivir la experiencia humana de comunicar? Eso dependerá de lo importante que sea para nosotros ser testigos de lo inconmensurable, es decir, el ser narrador. Quizá haya que decir de modo más contundente que la relación entre memoria y narrador, se mantiene viva por la riqueza que aportan la lejanía y la distancia, pues en varias ocasiones asumimos que contar algo es acercarlo o hacerlo propio, curiosamente diríamos que el arte de narrar consiste en mantener lo lejano como lejano, trabajo que no le interesa precisamente a aquellos que intervienen en asuntos de la comunidad. Me pregunto qué diría Benjamin sobre las discusiones que se libran en favor de la conservación del patrimonio 
ancestral. Así, entre memoria y narrador existe una tensión constante en razón de que la novedad a la que me refería al inicio de esta conversación, no constituye de modo alguno la aparición de lo grandioso o de lo revelador, sino más bien la inconmensurabilidad del tiempo y de la historia que hunde el asunto narrado en la vida misma. Queda pues por discutir si la narración, necesariamente excluye el silencio de la indignación o la vergüenza.

\section{Bibliografía:}

Claudel, Philippe. (2006) La nieta del Señor Lihn. Editorial Salamandra: España

Ricoeur, Paul. (2008) Vivo hasta la muerte. Fondo de Cultura Económica: México

Ricoeur, Paul. (2006) La vida un relato en busca de narradoren Ágora Papeles de Filosofía. Volumen 25, No. 2, p: 9-22

https://minerva.usc.es/bitstream/10347/1316/1/Ricoeur.pdf

Benjamin, Walter(2012)El narrador en Escritos Franceses. Amorrortu: Buenos Aires 